\title{
The Fate of Repository Gases (FORGE) Project RP Shaw
}

Understanding the behaviour of gases in the context of radioactive waste disposal is a fundamental requirement and was the focus of the FORGE project. Of particular importance, are the long-term performance of bentonite buffers and cement based backfill materials that may be used to encapsulate and surround the waste in a repository for the geological disposal of radioactive waste and plastic clays, indurated mudrocks and crystalline formations that may be the host rocks of a repository. FORGE did not study salt host rocks or salt based backfill materials. FORGE has provided new insights into the processes and mechanisms governing gas generation and migration with the aim of reducing uncertainty relating to the quantitative treatment of gas in performance assessment. This has been achieved by the acquisition of new experimental data coupled with modelling through a series of laboratory and field-scale experiments (performed at a number of underground research laboratories throughout Europe) and modelling. New methods were developed for up-scaling from laboratory to field conditions allowing the optimisation of disposal concepts through detailed scenario analysis. Understanding a repository system to an adequate level of detail is required to demonstrate confidence in the assessment of site performance, recognising that a robust treatment of uncertainty is desirable throughout this process.

\section{Introduction}

The European Commission FORGE (Fate Of Repository GasEs) project was a panEuropean project with links to international radioactive waste management organisations, regulators and academia, specifically designed to tackle some of the key research issues associated with the generation and movement of gases in the context of a repository for the disposal of radioactive waste. Work undertaken in the FORGE project will benefit a range of customers, e.g. implementers, regulators, industry and academia, via the provision of new information and understanding into gas-relevant features, events and processes (FEPs), including mechanisms governing gas generation and migration, for consideration in the safety case. It will also be of interest to other sectors with an interest in the migration of gas through low permeability geological materials.

The outcomes of the FORGE project have been detailed in a series of summary reports prepared under each of the projects work packages:

WP1 D1.05-R Synthesis Report: Updated treatment of gas generation and migration in the safety case (Norris; 2013);

WP2 D2.05-R Synthesis of experimental processes governing gas generation (Dobrev et al; 2013);

WP3 D3.38-R Experiments and modelling on the behaviour of engineered barrier system (EBS) (Sellin; 2014);

WP4 D4.24-R Summary report: Experiments and modelling of excavation damage zone (EDZ) behaviour in argillaceous and crystalline rocks (Harrington et al; 2013);

WP5 D.19-R Final Report: Experiments and modelling of gas migration processes in undisturbed rocks (Jacops et al; 2014).

These and all other reports produced by the FORGE project are available from the project web site at FORGEproject.org in pdf format.

This book brings together some of the work undertaken within the FORGE Project together with related work undertaken elsewhere. 


\section{Multiple Barrier Concept for Geological Disposal}

A safety case for a repository is a set of claims concerning the environmental safety of the geological disposal of radioactive waste in a repository, substantiated by a structured collection of arguments and evidence. Such a safety case needs to address environmental safety at the time of disposal and in the long-term, after wastes have been emplaced and the facility has been closed. Materials emplaced underground will slowly degrade and even the most stable geological environments will eventually change with the passage of geological time; the hazard potential of the wastes also decreases by radioactive decay. A safety case looks at the balance of these processes so that we can evaluate the environmental safety of a repository far into the future, as well as at the time of disposal.

An intrinsic part of developing a safety case for a geological repository is the consideration of the various FEPs that could affect the long-term environmental safety of the repository. This can be done by identifying FEPs that are relevant to the performance of a particular disposal concept, or using existing international FEP lists, with the intention being to analyse systematically all potentially relevant FEPs, thereby ensuring that the safety case is comprehensive in its coverage. Development of process models, component models and a total system model are integral aspects of a safety case.

The multiple barrier concept is the cornerstone of all proposed schemes for the geological disposal of radioactive wastes. Based on the principle that uncertainties in performance can be minimised by conservatism in design, the concept invokes a series of complementary barriers, both engineered and natural, between the waste and the surface environment. Each successive barrier represents an additional impediment to the movement of radionuclides.

For low and intermediate level waste (L-ILW), the waste may be incorporated in a relatively stable and inert matrix such as cement, bitumen, lead-alloy, polymer resin (the choice varying depending on the waste management organisation). In the case of certain high level (HLW) reprocessing wastes, glass may be used. Because of the very low leach-rate of glass in groundwater, vitrification is widely accepted to be one of the best methods of immobilising the aqueous products from the reprocessing of spent fuel (SF) (Ojovan and Lee; 2005). Many waste containers will provide some form of physical barrier to groundwater. However, because of the relatively small volumes of waste involved, spent fuel, vitrified waste and other highly active wastes may be totally encapsulated in corrosion-resistant metal canisters which are designed to prevent groundwater entry for very extended time periods in excess of 100,000 years (SKB; 2004).

Depending on the disposal concept, engineered barriers may comprise the buffer/backfill medium enclosing the waste containers, the tunnel/borehole liner, and the backfill and high integrity seals placed in the repository access ways or emplacement boreholes. The buffer/backfill medium enclosing the waste will often also provide both a physical and a chemical barrier to radionuclide migration. The functions of the engineered barriers are:

- To reduce the rate of corrosion of the waste containers and thus extend their life;

- To limit the rate of hydraulic transport;

- To limit the release of radionuclides from the waste-form to the far-field (geosphere) in the event of container failure;

- To limit the migration of radionuclides along the pathway provided by the access tunnels and shafts of a repository or the boreholes in the case of a deep borehole emplacement.

For L-ILW disposal in vaults, the backfill may be a porous, cementitious grout, which is intended to $\mathrm{pH}$-buffer the pore water for an extended time period. Typically the 
buffer/backfill for HLW/SF might comprise compacted bentonite or other clay-based material, providing a low permeability, alkaline $\mathrm{pH}$-buffered pore water to limit solubility and mobility of certain radionuclides (e.g. actinides), plus good retention/retardation properties including high sorption and a capacity to filter colloids.

The geological barrier is the final impediment to radionuclide migration. Depending on details of the local geology, this may be considered to constitute the host formation itself, extending above, below and laterally away from the repository. Alternatively, the entire sequence of low permeability rocks, which may separate the repository from the surface and/or more permeable, water-bearing, strata may be included. The practical realisation of the multiple barrier concept is the primary objective of all stages of a disposal programme, from site appraisal and characterisation through to design and construction. The general performance of the repository as a whole (waste, engineered barriers, excavation damage zone (EDZ), host rock), in particular its gas transport properties, is being intensively studied in many national programs. Issues relating to basic process understanding related to gas transport such as dilational versus displacement flow mechanisms, the long-term gas transport characteristics of seals, gas flow along interfacial contacts and up-scaling from laboratory to field conditions are a particular focus of study.

\section{Gas in the Context of Geological Disposal of Radioactive Waste}

Within a repository and assuming the availability of groundwater, corrosion of various metals and alloys, in particular ferrous materials, under anoxic conditions will lead to the formation of hydrogen. Radioactive decay of the waste and the radiolysis of water particularly will produce additional gas. If present, biodegradable wastes will produce carbon dioxide and methane through microbial action and other (minor) gaseous species may also be generated. If groundwater is not available, the gas generation rate will be very low to insignificant, although the potential gas source itself (e.g. corrosion of ferrous materials), will persist. If the gas production rate exceeds the rate of diffusion of gas molecules in the pores of the engineered barrier or host rock, the solubility limit of the gas will eventually be exceeded, leading to the formation of a discrete gas phase. Gas would continue to accumulate until its pressure becomes sufficient for it to enter the engineered barrier or host rock. Understanding gas generation and migration is thus one of the key issues in the assessment of repository performance (Johnson; 2006) and is the focus of the FORGE project. The generation of gases in the repository environment is of concern for a number of reasons (Rodwell et al; 1999):

- Pressurisation of waste containers;

- Perturbation of any groundwater flux;

- Effect on host rock mass transport properties;

- Effect on repository backfill and seals;

- Effect on the EDZ and self-sealing properties;

- Effect on heat dissipation;

- Release of active gases;

- Displacement of contaminated groundwater.

The impact of gas generation on repository infrastructure and evolution has been the source of several pan-European projects/initiatives during the last decade including GASNET (Rodwell et al; 2003). Of particular importance was the fundamental review undertaken by Rodwell et al. (1999) which assessed the current state-of-the-art knowledge in relation to gas generation and migration in repository systems and the GASNET project, completed in 2003, (Rodwell et al; 2003) project which dealt with the treatment of gas in repository performance assessment. 
These projects identified a number of uncertainties linked to the quantitative treatment of gas generation, migration and subsequent evolution of repository systems. Uncertainties identified in GASNET (Rodwell et al; 2003) of particular importance to FORGE are:

1. The definition of long-term corrosion rates of ferrous metals under repository conditions (which was considered in FORGE Work Package 2);

2. A better understanding of the processes and mechanisms governing gas migration in clay-based engineered barriers and host rocks (which was considered in FORGE Work Packages 3, 4 and 5);

3. The effect of elevated gas pressures on the movement of groundwater and aqueous borne contaminants (which was considered in FORGE Work Package 4);

4. The role of gas in the evolution of the near-field and the EDZ (which was considered in FORGE Work Package 4);

5. The possible coupling of effects to compromise repository performance (which was considered in FORGE Work Package 1).

The FORGE project addressed these research areas across five work packages.

The Work Packages in the FORGE project were:

- WP 1 Treatment of gas in performance assessment;

- WP 2 Gas generation;

- WP 3 Engineered barrier systems;

- WP 4 Disturbed host rock formations;

- WP 5 Undisturbed host rock formations.

To address these fundamental issues, the FORGE project has been structured in such a way as to provide new insights into the processes and mechanisms governing gas generation (WP2) and migration (WP3-5) through the acquisition of new experimental data, aimed at repository performance assessment (WP1). FORGE also helps to address the paucity of high-quality data currently available for future activities such as benchmarking and validation of numerical codes for the quantitative prediction of gas flow, the development of $\mathrm{HM}$ (Hydrogeological - Mechanical) models for the prediction of EDZ and near-field processes and to assist in the assessment of the long-term evolution of the potential geological barriers. In the ideal situation, gas would be in solution in the host-rock groundwater and would be transported away from the repository by advection/diffusion processes. Furthermore, attenuation mechanisms (e.g. chemical reactions) in the host-rock could result in depletion of the flux of gas in solution so that, at some distance from the repository, the radiological significance of the flux could be minimal. However it is paradoxical that the sought after characteristic of a host rock with very low permeability becomes somewhat problematic in the context of gas migration. Calculations of the probable maximum diffusive flux of gas (in solution) in a clay suggest that Fickian diffusion in the host rock may be too slow a mechanism to accommodate the quantity (and rate) of gas produced in a repository (Lever and Rees; 1988). This is, of course, highly dependent on specific details of the repository design and the waste inventory. Nevertheless, there is a strong possibility that a gaseous phase will accumulate in the available void space within a repository resulting in a rise in gas pressure. It seems highly unlikely that the high integrity seals constructed at key points in the repository could be engineered to withstand such a substantial differential pressure for an extended time-period. As gas pressure rises, it is inevitable that the gas entry pressure will be reached for the rock and /or repository sealing system. This may have consequences for the repository design and safety assessment, thus this aspect needs to be carefully examined. In 
low-permeability rocks, gas production and migration is likely to be an important issue, since these rocks cannot easily accommodate the gas flux. If gas production is likely to be significant, then its possible repercussions must be examined as an integral part of the hostrock/site selection process.

To fully understand the impact of gas generation and transport on current engineered barrier concepts, its effect on self-sealing within the EDZ and its long-term effect on the hydrogeological characteristics of the far-field, requires an integrated, multidisciplinary project to address these key research areas.

\section{This Volume}

The papers in this special publication present some of the results of the FORGE Project and related work undertaken elsewhere.

The results of laboratory based experimental studies have been described in several of the papers. Jacops et al (this volume) undertook column experiments designed to determine if gas-driven radionuclide transport through saturated Boom Clay could enhance migration. Based on their results, it can be concluded that the transport of radionuclides and contaminants, because of a gas breakthrough event, is possible but appears to be very limited with the volume of water displaced being very low compared to the volume of gas transported upon breakthrough.

Popp et al (this volume) performed hydraulic tests on pre-fabricated bentonite/sand-blockassemblies (60/40). The results of these experiments demonstrate that, despite existing interfaces, the investigated bentonite block assembly behave in the same way as the homogenous matrix during the saturation. The results convincingly demonstrate that the interfaces between bentonite bricks may "heal” (not only seal) after re-saturation.

Purser et al (this volume) undertook hydraulic and gas permeability tests on Nirex Reference Vault Backfill (NRVB) cement at $40^{\circ} \mathrm{C}$ and at either $4 \mathrm{MPa}$ or $8 \mathrm{MPa}$. Carbonation reactions, using CO2 gas, halved the permeability of the NRVB under simulated repository conditions. A greater decrease in permeability (by three orders of magnitude) was found during carbonation using dissolved CO2. Mineralogical changes occurred throughout the cement as a result of reaction with $\mathrm{CO} 2$. However, a narrow zone along the leading edge of a migrating reaction front was associated with the greatest decrease in porosity.

Gutiérrez-Rodrigo et al (this volume) determined gas breakthrough pressure values in saturated FEBEX bentonite for different dry densities and sample sizes. They increased clearly with dry density and were always higher than the swelling pressure of the bentonite. After re-saturation of the bentonite, the same breakthrough pressures and permeabilities were found, pointing to the perfect healing of these preferential pathways.

Villar et al (this volume) investigated gas transport properties of concrete samples using two different laboratory test setups. Permeability decreased with water content increase, but was also greatly affected by the hydraulic history of concrete. The intrinsic permeability determined with gas flow was about two orders of magnitude higher than that determined with liquid water (10-16 vs. 10-18 m2), probably because of the chemical reactions taking place during saturation (carbonation). The relative gas permeability of concrete increased sharply for degrees of water saturation smaller than $50 \%$.

Zhang (this volume) performed gas flow experiments by flowing nitrogen through fractured and resealed Callovo-Oxfordian and Opalunus Claystone samples under different hydromechanical conditions. Gas flow behaviour in water-saturated and resealed fractures is 
characterised by three key parameters namely gas breakthrough pressure, permeability and shut-in pressure. The experimental findings imply that the EDZ, even when highly-resealed, will still have the capacity for gas migration under moderate pressures.

Large scale gas injection tests carried out in Josef Underground Laboratory as part of the project aiming to study the behaviour of both the excavation damaged/disturbed zone (EDZ) and the undisturbed rock environment and described by Svoboda and Smutek (this volume). The tests performed revealed a significant difference in terms of gas permeability between the EDZ and the undisturbed rock mass.

Popp et al (this volume) review the current understanding of the gas transport properties associated with a radioactive waste repository in a salt environment where significant amounts of gas quantities may be generated in the long-term, for example, by anaerobic corrosion, if humidity is present.

The outcomes of modelling gas flow based on experimental data and repository concepts formed an important aspect of FORGE. Ahusborde et al (this volume) present the results of a benchmark study that compares a number of numerical models applied to a specific problem in the context of hydrogen flow and transport in a radioactive waste repository. They modelled two-phase (water and hydrogen) immiscible compressible two-component transient flow in a heterogeneous porous medium under isothermal conditions. The three-dimensional model represents a module of a repository for high level waste in a clay host rock. An upscaling technique and a vertex-centred finite volume method were employed to yield very accurate solutions.

Alcoverro et al (this volume) analysed the HG-A in-situ test, located at the Mont Terri URL. This test investigated the behaviour of the EDZ around a backfilled microtunnel by a series of water and gas injection tests. In their model, the intrinsic permeability of the EDZ was assumed to depend on deformation and additional simplifying assumptions were applied. The main trends of the pressure evolution observed in the test section were reproduced. A 2D axisymmetric model confirmed the validity of the simplifying assumptions, except for small zones of the EDZ near the megapacker ends.

Dymitrowska et al (this volume) describe an improved mathematical and physical description of two phase flow in tight porous media in order to model hydrogen migration within a geological repository for radioactive waste. Contrary to existing approaches, they are interested in avoiding the need to switch primary variables during calculations and they show that it is possible to work with universal primary variables to describe correctly gas phase appearance/disappearance.

The results of a series of numerical simulations of the reactive transport of hydrogen in unsaturated bentonite are presented by Sedighi et al (this volume), in which hydrogen gas has been injected into a partially saturated bentonite buffer. The results show the high buffering capacity of unsaturated bentonite, when considering a steel canister, over a period of 10,000 years. The presence of accessory minerals is shown to have an important role in mitigating excess hydrogen ions, thus increasing the dissolution capacity of the system to gas. Development of various forms of aqueous complexations between the inorganic components and hydrogen ions were also found to be important in buffering the excess hydrogen evolved. Based on their results they postulated that the presence of various chemical components in the clay buffer may influence the transport and fate of the hydrogen gas.

Shoa et al (this volume) have developed a fully coupled hydro-mechanical model taking account of elastic and plastic anisotropies, anisotropic two-phase flow based on the van Genuchten function, and permeability changes to evaluate the experimental data from several 
experiments in the Mont Terri Rock Laboratory. The gas flow regime in a large scale experiment was by the excavation induced fractures around the opening with a permeability of four order of magnitude higher than those in the undisturbed rock mass.

Coupled hydro-mechanical modelling and analyses have been carried out by Yamamoto et al (this volume) in order to evaluate the mechanical stability of the engineered barrier system. They have found from their analyses that tensile stress developed in the cementitious components as a result of the accumulated gas pressure is lower than the tensile strength of the. These results indicate that the gas pressure would not mechanically damage the engineered barrier system of the sub-surface disposal even if a relatively high gas generation rate is assumed.

In order to interrogate the dataset arising from the Large Scale Gas Injection Test (Lasgit), a field scale experiment designed to study the impact of gas build-up and subsequent migration through an Engineered Barrier System (EBS), a bespoke computational toolkit, designed to expose and quantify difficult to observe phenomena in large, non-uniform datasets, has been developed and applied by Bennett et al (this volume). They present results focused on the investigation and interpretation of second order events occurring in close proximity (temporally and spatially) to a known macro scale gas flow event that occurred during the Lasgit second gas injection test. The similarity of the investigated event to dilatant flow observed in laboratory experiments and the evidence for localised flow pathways in the bentonite EBS are noted.

This volume is concluded by a paper by Norris (this volume) that summarises overall understanding on the implications of gas generation and migration for the safety functions of the Engineered Barrier System (EBS) and the host rock as informed by the output of the FORGE project. Achievements and recommendations from the FORGE project are noted, emphasising that FORGE has provided confidence in the basic physical understanding and modelling approaches relevant to GDF-derived gas that can be applied for different concepts - such understanding, and the derived component and system models, can be used in a safety case to address regulatory guidance.

\section{Acknowledgements}

This summary is based on summary reports prepared by each work package. The work package leaders who prepared these reports and the authors that contributed to them are thanked for their contributions which have been used here. All organisations participating in FORGE and personnel are thanked for their scientific contribution to the project. The partners in the FORGE project are:

Natural Environment Research Council - British Geological Survey (BGS) - UK

Nuclear Decommissioning Authority (NDA) - UK

Svensk Kärnbränslehantering AB (SKB) - Sweden

Studiecentrum voor Kernenergie/Centre d'Etude de l'Energie Nucléaire (SCK-CEN) Belgium

Agence nationale pour la gestion des déchets radioactifs (ANDRA) - France

Commissariat à l'Énergie Atomique (CEA) - France

Centro de Investigaciones Energéticas, Medioambientales y Tecnológicas (CIEMAT) - Spain

Centre Internacional de Mètodes Numèrics en Enginyeria (CIMNE-UPC) - Spain

Centre National de la Recherche Scientifique (CNRS) - France 
Ecole Nationale de Chimie de Lille, Laboratoire de Mécanique de Lille (LML) - France

Electricite de France-SA (EDF) - France

Gesellschaft für Anlagen- und Reaktorsicherheit mbH (GRS) - Germany

National Cooperative for the Disposal of Radioactive Waste (NAGRA) - Switzerland

Université de Liège (ULg) - Belgium

Posiva Oy (Posiva) - Finland

Centre of Experimental Geotechnics, Czech Technical University in Prague (CTU-CEG) Czech Republic

Nuclear Research Institute - Rez (NRI) - Czech Republic

Institut de Radioprotection et de Sûreté Nucléaire (IRSN) - France

Regiei Autonome "Tehnologii pentru Energia Nucleara” (RATEN) - Romania

Institut für Gebirgsmechanik GmbH (IfG) - Germany

Lietuvos Energetikos Institutas (LEI) - Lithuania

Eidgenössisches Nuklearsicherheitsinspektorat (ENSI) - Switzerland

Federaal Agenschap voor Nucleair Controle (AFCN-FANC) - Belgium

Radioactive Waste Repository Authority (RAWRA) - Czech Republic

This paper is published with the permission of the Executive Director of the British Geological Survey. The European Commission is acknowledged for its funding of this panEuropean project which has received funding from the European Atomic Energy Community’s Seventh Framework Programme (FP7/2007-2011) under Grant Agreement no 230357.

\section{References}

Ahusborde, E., Amaziane, B., and Jurak, M., 2015, 3D numerical simulation by upscaling of gas migration through engineered and geological barriers for a deep repository for radioactive waste, this volume.

J. Alcoverro, J., Olivella, S., and Alonso, E.E., 2015, Modelling fluid flow in Opalinus Clay EDZ. A semianalytical approach, this volume.

Bennett DP, Cuss RJ, Vardon PJ, Harrington JF, Sedighi M, and Thomas HR., 2015, Exploratory data analysis of the Large Scale Gas Injection Test (Lasgit) dataset, focusing on 'second order' events around macro scale gas flows, this volume.

Dobrev, D., Stammose, D., Pellegrini, D. and Vokal, A., 2013. FORGE Work Package 2 Final Report Experimental Studies on Hydrogen Generation by Corrosion. EC FORGE Project Report D2.5-R. 53p.

Dymitrowska, M., F. Smaï, F., and Bourgeat, A., 2015, Thermodynamic Modelling of Hydrogen Migration in Argillite for a Deep Geological Radioactive Waste Repository - IRSN contribution to FORGE, this volume.

Gutiérrez-Rodrigo, V., Villar, M-V., Martín, P L., Romero, F J., and Barcala, J M., 2015 Gas Breakthrough Pressure of Febex Bentonite, this volume.

Harrington, J., Volckaert, G., Jacobs, E., Maes, N., L.Areias, Charlier, R., Frédéric, C., Gerard, P., Radu, J-P., Svoboda, J., Granet, S., Alcoverro, J., Arnedo, D., Olivella, S., Alonso, E., Marschall, P., Gaus, I., Rüedi, J., Cuss, R., Sathar, S. and Noy, D. 2013. Summary report: Experiments and modelling of excavation damage zone (EDZ) behaviour in argillaceous and crystalline rocks (Work Package 4). EC FORGE Project Report D4.24-R.

Jacops, E., Volckaert, G., Maes, N., Charlier, R., Collin, F., Gerard, P., Levasseur, S., Delavaissière, R., Talandier, J., Granet, S., Navarro, M., Villar, M-V., Romero, F., Martin, P., Zandarin, M., Olivella, S., Alonso, E., Marschal, P., Cuss, R., Harrington, J., Sathar, S., Noy, D. and Wood, A., 2014. WP5 Final Report: Experiments and modelling of gas migration processes in undisturbed rocks. FORGE Report D5.19. 131pp. 
Jacops, E., T. Maes, T., Maes, N., G. Volckaert, G., Weetjens E., Sillen, X., 2015 Gas-driven radionuclide transport in undisturbed and disturbed Boom Clay, this volume.

Johnson, L.H. 2006. Gas Production and Transport in the Near Field of SF and HLW Repositories in Clay and Crystalline Rocks: Processes, Uncertainties and Performance Assessment Aspects. NF-PRO (contract No F16W-CT-2003-02389) report (deliverable D-No: 5.1.6).

Lever, D.A. and Rees, J.H., 1988. Gas Generation and Migration in Waste Repositories. pp. 115-127 in Nuclear Energy Agency, 75; 314 p; ISBN 92-64-03060-3; NEA workshop on near-field assessment of repositories for low and medium level radioactive waste; Baden (Switzerland); 23-25 Nov 1987; Nuclear Energy Agency of the OECD (NEA): Organisation for Economic Co-operation and Development; Paris (France).

Norris, S., (ed). 2013. Synthesis Report: Updated Treatment of Gas Generation and Migration in the Safety Case FORGE Report D31.5R. 116+ixpp.

Norris, S., 2015, EC FORGE PROJECT: Updated Consideration of Gas Generation and Migration in the Safety Case, this volume.

Ojovan, M.I. and Lee, W.E. 2005. An Introduction to Nuclear Waste Immobilisation Elsevier ISBN: 0-08044462-8, 250p.

Popp, T., Rölke, R., and Salzer, K., 2015 Hydro-mechanical Properties of Bentonite/Sand-Block-Assemblies with interfaces in Engineered Barrier Systems, this volume.

Popp, T., Minkley, W., Wiedemann, M., and Salzer, K., 2015 Gas-pressure induced integrity of salt formations, this volume.

Purser, G., Milodowski, A E., Noy, D J., Rochelle, C A., Harrington, J F., Butcher, A., and Wagner, D., 2015 Modification to the flow properties of repository cement as a result of carbonation, this volume.

Rodwell, W.R., Harris, A.W., Horseman, S.T., Lalieux, P., Müller, W., Amaya, L.O. and Pruess, K. 1999. Gas migration and two-phase flow through engineered and geological barriers for a deep repository for radioactive waste: a joint EC/NEA Status Report. Nuclear Energy Agency and European Commission Nuclear Science and Technology Report EUR 19122 EN ISBN 92-828-8132-6. . European Commission, Luxembourg. 429p.

Rodwell, W., Norris, S., Cool, W., Cuñado, M., Johnson, L., Mäntynen, M., Müller, W., Sellin, P., Snellman, M., Talandier, J., Vieno, T. and Vines, S., GASNET 2003. Euratom, a thematic network on gas issues in safety assessment of deep repositories for radioactive waste. Final Report on the treatment in safety assessments of issues arising from gas generation.

Sedighi, M., Thomas, H R., Al Masum, S., Vardon, P J., Nicholson, D. and Chen, A, 2015, Geochemical Modelling of Hydrogen Gas Migration in Unsaturated Bentonite Buffer, this volume.

Sellin P. (editor). 2014. Experiments and modelling on the behaviour of EBS. FORGE Report D3.38.426pp.

Shao, H., Xu, W., Marschall, P., Kolditz, O., and Hesser, J., 2015, Numerical Interpretation of Gas Injection Tests at Different Scales, this volume.

SKB 2004 Interim main report of the safety assessment SR-Can Technical Report TR-04-11, Svensk Kärnbränslehantering AB.

Svoboda, J., and Smutek, J., 2015, The Experimental In-Situ Study of Gas Migration in Crystalline Rock with a Focus on the EDZ, this volume.

Villar, M-V., Martín, P L., Romero, F J., Gutiérrez-Rodrigo, V., and Barcala, J M., 2015, Gas and Water Permeability of Concrete, this volume.

Yamamoto, S., Kumagai, M., Koga, K., and Sato, S., 2015, Mechanical Stability of Engineered Barriers in Subsurface Disposal Facility during Gas Migration Based on Coupled Hydro-Mechanical Modelling, this volume. 
Zhang, C-L., 2015, Investigation on Gas Migration in Damaged and Resealed Claystone, this volume. 